\title{
Routine innovation: complex processes from policy development to implementation
}

\author{
Rob Warwick \\ Centre for Sustainable Business \\ University of Chichester Business School \\ University of Chichester \\ Upper Bognor Road \\ Bognor Regis \\ PO21 1HR \\ UK \\ E-mail: r.warwick@chi.ac.uk
}

\section{Keywords}

Routine innovation, change management, group dynamics, noticing, complexity, social process, narrative, policy development, process, temporal, power relations

Biographical Notes: Rob Warwick is a senior lecturer at the University of Chichester Business School in the UK. His areas of interest include strategy and leadership, an interest borne form his role as Head of Stratgic Change for a large organisation within the UK's National Health Service and latterly in a number of academic roles. He runs the Business School's MA in Management and Leadership and the day release BA Business degree; he also supervises $\mathrm{PhD}$ students. His research approaches are largely qualitative and include reflexivity and action research.

\begin{abstract}
Routines of working relationships inhibit the noticing of group norms, behaviours and assumptions (Alvesson and Spicer, 2012). Changing those routines, with the formation of temporary organisational relationships such as a policy group, creates a social noticing whereby propositional themes are interpreted and new ways of working can be imagined. The paradox of stability/instability of such groupings enables an innovating process to develop leading to new routines and power relations. Complex responsive processes of relating (Stacey et al., 2000) draws attention to these processes in ways that are helpful for the policymaker. For example, in addition to the policymaker's work in drafting policy, it encourages attention to be paid to the ongoing social interactions as policy is made and interpreted in different groups and in different contexts. Heightened awareness enables greater individual and social reflexivity and increases the potential for successful innovation.
\end{abstract}

\section{$1 \quad$ Introduction}

In a review on innovation, Baregheh and colleagues (Baregheh et al., 2009) explain that it is a 'multi-stage process whereby organisations transform ideas into new/improved products,

Page 1 of 18

Warwick R (2016) Routine innovation: complex processes from policy development to implementation, International Journal of Business and Globalisation, Vol 17, No 4, p541-555 
service or processes, in order to advance, compete and differentiate themselves successfully in their marketplace'. They draw attention to the nature of process in innovation, often spanning years with different groups with varying inter and intraactions.

Some of these intra/interactions may be straightforward to predict, but others are difficult to explain. This has implications for policymakers and others who see the value of innovation but are often frustrated as to how this might be enabled. A recent evaluation of a regional innovation initiative explains the challenges for policymakers, particularly across different organisations and professional sectors (Brighton Fuse, 2014, 2015). They make the point that whilst the development of clusters and interdisciplinary workings are important in facilitating innovation they are difficult to replicate. The dynamic mix of economics, people, culture and institutional support makes intervention difficult and unpredictable.

Using a case study spanning several years this paper explores this dynamic as a part of the innovation process itself; that of destabilizing the routines of working relationships. I have termed this 'routine innovation'; a term recognising the importance of the intentional and emergent disturbance of routine to encourage innovation.

I will illustrate routine innovation with a number of connected narratives spanning two years. These narratives were part of my experience as a policy maker/strategist in healthcare working on improving organ donation in the UK. This innovation was not radical or surprising; that said over a five year period it led to an increase in organ donation by $50 \%$ (BBC, 2013).

The nature of innovation and group interaction has been a source of research and interest, particularly amongst those who have experienced it in relation to the nature of knowledge (Polanyi, 1958) and how these processes might be understood and used in other fields (Checkland and Poulter, 2006; Revans, 1998). Alvesson and Spicer, in a paper titled 'A Stupidity-Based Theory in Organisations', explored the beneficial and negative dynamics between routines of longstanding working relationships and how these inhibit the noticing of group norms and assumptions and that of greater noticing and reflexivity and its impact on facilitating innovation (Alvesson and Spicer, 2012). For George Orwell too it was a theme he explored in his dystopian novel 1984 describing it as a 'protective stupidity' (Orwell, 1949, p182).

Through a series of narratives Fonseca (Fonseca, 2002), explores innovation as a patterning of social processes, through which new meanings emerge. I will draw attention to how the formation of new groups, for example a taskforce, disturbs long established power relations enabling different conversations, exploration, noticing and meaning to occur. In discussing power relations I draw on the sociologist Norbert Elias's notion of figurational power, namely that it is not an object of possession, but rather shifting patterns of influence between individuals and/or groups (Elias, 1978, p128-133), (Burkitt, 1991, p163-165).

These groups are creatively unstable; the risk of fracture is ever present, yet this is essential in enabling consensus and new patterns of working to emerge. It is paradoxical. They

Page 2 of 18

Warwick R (2016) Routine innovation: complex processes from policy development to implementation, International Journal of Business and Globalisation, Vol 17, No 4, p541-555 
consider propositional themes, such as governmental desire to increase organ donation, and create new propositional themes to be considered by other groups. By way of definition a 'propositional theme' is an artefact (eg strategy, policy or instruction) or conversation that is being interpreted as a desired future state. It has been communicated by a powerful group or individual to another group with the aim to interpret it in the context of their situation. These are taken up locally where new groups are formed and where similar creative unsettlement occurs.

I use the words 'notice' and 'explore' deliberately as this process is reflexive, both individually (Cunliffe, 2009) and as a group process (Warwick \& Board, 2013).

This has implications for research method and practice because both are reflexive and emergent.

\section{$2 \quad$ Method}

Narrative was the principal means of data collection, written close to the time of the event occurring and interpreted both at the time and several years later. It was used to record group interactions, including my own involvement, during the research process (Ellis and Bochner, 2000; Stacey and Griffin, 2005; Stacey, 2003). They were written by me in my role as a strategist and later being responsible for the implementation of a frontline service. I engaged with them in two ways, a narrative mixed method approach: firstly, at the time of their drafting, contributing to my doctoral research; and secondly, five years later in a series of conversations. The process was highly reflexive (Cunliffe, 2002; Ellis and Bochner, 2000; Johnson and Duberley, 2003; Ramsey, 2014).

The prompts for writing narratives included one or more of the following characteristics: a collective recognition of their importance, for example a policy launch; shifts or jarring in collective thought, for example the consequences of a provocative intervention; or, an experience that shifted my assumptions, for example attending a surgical operation.

The narratives explore three interconnected areas through the process from policy formation to frontline implementation.

The first looks at the workings of a government taskforce; including how it worked in confidence and built trusting relationships (Mayer et al., 1995; Möllering, 2006) amongst groups with historical differences.

The second addresses the publication of the taskforce's recommendations and ministerial endorsement, and how the taskforce's own propositional themes were publically shared and in turn made sense of.

And finally, how an organisation I worked for came to further interpret the taskforce's propositional themes creating its own in the form of strategy that was in turn interpreted by frontline staff.

Page 3 of 18

Warwick R (2016) Routine innovation: complex processes from policy development to implementation, International Journal of Business and Globalisation, Vol 17, No 4, p541-555 
These narratives were written up within a few hours of the events between 2008 and 2010 so as to reduce post-hoc rationalisation that would otherwise downplay ambiguity and the multiple threads of possibility that exist in the moment. They were written in the first person and draw attention to contradictions, sensemaking and emotions that I was noticing at the time. They were then discussed at a doctoral learning group meeting enabling me to further notice my underlying assumptions and patterns of thought (Warwick and Board, 2012).

The narratives draw attention to anticipation, interpretation, sensemaking, hope, doubt etc as people come to understand the propositional themes that they have been offered. In these processes the narratives demonstrate the nature of changing power relations and the noticing this enabled across groups. Small detail is also included; not as 'colour', but to illustrate how small gestures or events came to have a significant effect.

A series of conversations some five years later prompted further reflective writing over the summer of 2014 and the narratives were revisited in a process of explication (Franklin, 2007; Kreiner, 2002; MacKenzie and Franklin, 2006). Here implicit knowledge is made explicit, recognising that: ' ... much of our learning takes place silently, simmering away as a sort of subversive process that we only know about when we are suddenly surprised by our knowledge and skills due to a new unexpected event, like a challenge, an accident or a crisis of some sort' (Franklin, 2007, p52). These conversations challenged how I came to reflect on my experience and the means by which I made sense of them. This included observations on the patterns of interaction that occurred, philosophical underpinnings, my role in the activity and the knowledge of the impact that the policy work had achieved.

\section{The experience of complex relating}

Ralph Stacey and others developed approaches that paid attention and described the ordinariness of everyday social interaction, termed complex responsive processes of relating (Griffin, 2001; Shaw, 2002; Stacey et al., 2000; Streatfield, 2001). Here complexity is used as an analogy to explore human interaction as ongoing temporal processes. They draw their philosophical heritage to that of Hegel; and to those influenced since such as G.H. Mead, Bourdieu, Elias and Weick. They offer a way of understanding experience that emphasises that we are part of that experience and not isolated from it. It is a way of thinking about human interaction and power, but not as a framework or tool of the detached observer. They draw our attention to how we come to understand and how we 'rub along' with each other in the activity of organising as we seek to achieve some goal. It relates to the nature of the anticipatory processes of human relating from which we can explore change. It keeps centre stage the ongoing nature of communication in the form of gesture from one party and how this response is reacted to by another (Mead, 1934), (Stacey, 2007, p271-273). Attention is therefore paid to ordinary everyday experience and seeks to avoid abstracted generalisations. As Stacey and Griffin (Stacey \& Griffin, 2005) point out, it enables understanding of organisations as ongoing widespread patterns of interaction between people, influenced by propositional themes and how these are played out in local interactions. Understood in this way, individuals cannot step outside of their interaction with others; this is because our

Page 4 of 18

Warwick R (2016) Routine innovation: complex processes from policy development to implementation, International Journal of Business and Globalisation, Vol 17, No 4, p541-555 
identities and actions are always a part and a product of ongoing processes. It is an approach that is essentially qualitative, understood with the use of narrative and reflexivity to understand what we are all doing together. It pays attention to organisations (or more importantly the processes of people coming together and organising) as patterns of interaction where there is both consistency and novelty emerging. There is close connection with the idea of time as developed by GH Mead, the American pragmatist philosopher. Within the chapter, 'The Present as the Locus of Reality' in a collection of works under the title The Philosophy of the Present Mead wrote:

The pasts that we are involved in are both irrevocable and revocable. It is idle, at least for the purpose of experience, to have recourse to a 'real' past within which we are making constant discoveries; for that past must be set over against a present within which the emergent appears, and the past, which must be looked at from the standpoint of the emergent, becomes a different past (Mead, 1932, p36).

This anticipatory view of time, from which the immediate past and present are being constructed are re-constructing each other, thus enabling a constrained transformative novelty to emerge. This way of working with time is different from the way time in organisations is normally thought about, namely as featureless sweeps that encompass strategy and policy, marked by targets and performance indicators. With time viewed in this way complex responsive processes of relating enables us to notice paradox as an ubiquitous part of human experience as we 'rub along' with each other (Stacey, Griffin, \& Shaw, 2000). These processes invite gestures which are then responded to in ways that are both predictable and unpredictable within the shifting power figurations, but in which patterns of interaction emerge. These processes are paradoxical in a way that is 'realistic' of everyday life. Thought of in this way power is neither good nor bad but simply a feature of the agency by which we engage with each other both consciously and unconsciously. Elias makes the case that power can be thought of as threads of elastic, or figurations, between people. In addition to the here and now Elias, in his book the Civilising Process (Elias, 2000) points out that power can come to affect people over many generations, in other words beyond those who are in the room.

Stacey and others are critical of many organisational research methodologies (Stacey \& Griffin, 2005b) for their spatial stance which implies that we can step back from experience and analyse what has happened. In doing so their argument is that we reduce the experience of process. The use of personal narrative and reflexivity offers a more temporal, anticipatory and provisional way to account for experience in the flux of knowing and not knowing (Warwick and Board, 2012).

In summary, therefore complex responsive processes of relating offers a way to consider interactions between people as they engage in the anticipatory endeavour of organisational life. In order to speak of the ongoing and conflicting activities it is appropriate to rebalance, away from metaphors (Lackoff and Johnson, 2003) that are spatial in favour of attention towards the temporal flow of experience. It is here that the rich texture of human relating

Page 5 of 18

Warwick R (2016) Routine innovation: complex processes from policy development to implementation, International Journal of Business and Globalisation, Vol 17, No 4, p541-555 
becomes more accessible through the use of appropriately constructed narratives. A temporal process way of thinking allows voice to be given to those ongoing tensions and paradoxes that seem to be essential in the way people 'rub along'. 


\section{$4 \quad$ Connected narratives}

\section{Background}

The organisation I worked for was supporting England's Department of Health in facilitating the Taskforce (The Department of Health, 2008), providing resources and would also be responsible for some of the recommendations they might make if adopted.

The taskforce included senior transplant surgeons (who treat patients in desperate need of transplants) and intensive care doctors (who have developed a relationship with the donors' families). Both situations have life changing implications for patients and families and both are very emotional; add to this the different professional identities of both groups leading to intragroup allegiances and intergroup mistrust. Others on the Taskforce included ethicists, economists, commissioners, strategists and so on. It was chaired by an experienced chairperson who had extensive experience of the UK's National Health Service at very senior levels.

In terms of context, organ donation in the UK was not performing well by international comparison. Different groups had sought to investigate the problems and make recommendations; reports were written and recommendations made but little coordinated action was taken leading to frustration in the transplant community and the setting up of the Taskforce.

\section{Narrative: The taskforce at work - private tension}

Like many taskforces its discussions and workings were in confidence; here is the narrative of one such meeting:

The meeting was held in the basement of a government building where a group of disparate individuals had come together as a taskforce. We had been working together on this for several months. It was a big room, with tables arranged in a large square. The room was newly refurbished, but with little natural light. At previous meetings there had been a tendency for those with differing views to sit as far apart from each other as possible, and so it was this time.

Together with the chairperson, I was one of the first to arrive. She confided that she was worried that one of the members might 'walk out' and put the success of the initiative in jeopardy. I noticed that she had a couple of large boxes she had brought with her. It turned out later that she had made some cakes for people to share during morning coffee. This created a lot of interest and affected the conversation. The previously difficult and tense exchanges stopped as people became directed towards the cakes. People recounted their favourite recipes; giving a small insight to their home life.

It occurred to me that there would not be many opportunities for such a diverse range of people to be in the same room together, not only because of their different professional and social circles, but because of a professional dislike and mistrust

Page 7 of 18

Warwick R (2016) Routine innovation: complex processes from policy development to implementation, International Journal of Business and Globalisation, Vol 17, No 4, p541-555 
between some. This point had been made clear before the meeting when one of the surgeons had publicly and in writing described another professional group as being 'slippery'. At the heart of this difference were very real professional, ethical and legal difficulties and ambiguities.

Prior to the meeting I had sent around the latest draft of my report, a 'work in progress' that sought to capture the developing thoughts of the group at the time. Just before we sat down a couple of people came up to me and said how well the report was coming along and how amusing some of the minor typographical errors were. My Chief Executive came over to me to ask if there was anything he needed to do to support me.

I stood up to present the paper. There was quiet, attentive listening, but little in the way of active engagement. But then a point came where I felt that I was at the centre of the meeting's anxiety and tension. There were comments that the report was unbalanced, with too much attention paid to supply chain issues at the expense of clinical concerns; the terminology I had used was wrong, and so it went on. It is difficult, or impossible, to untangle my feelings of anxiety. I felt myself wishing that I was somewhere else. I felt confused, as if I had missed something, a part of the jigsaw. After the meeting a couple of people came up to me to express surprise at what had happened and speculated about other private meetings that must have happened behind the scenes.

Later the events of the day went through my mind. It was at this point it started to occur to me that there was more to the discussion of the report, and my reaction to it, than appeared at first. The report was one example where conflict surfaced, just as the cakes were a focus for connection. Conflict and collaboration were constantly emerging in an unstable, surprising and interdependent way.

Here I provide an example that affected me. At a later meeting one prominent individual said to an economist, having finished his presentation on the cost benefits of organ transplantation: '. . a and that's why health economists should have nothing to do with health'. And we have already heard the accusation of slipperiness.

Each person came to this meeting representing their own constituency with their own power base, in which conversations about the Taskforce were occurring. During breaks there were 'corridor musings' as to whether these constituencies would go along with a growing consensus of Taskforce members.

What I am pointing to is the shifting and occasional dramatic jolting of power relationships between individuals of differing traditions and allegiances and the emerging new allegiances that were starting to occur in the taskforce. Members were mindful of their own identity and those that they aligned themselves to; mostly this was implicit, occasionally explicit. For example the comments on terminology I used and how they would be interpreted by others despite using similar phrases in conversation. There was also talk as to how they would

Page 8 of 18

Warwick R (2016) Routine innovation: complex processes from policy development to implementation, International Journal of Business and Globalisation, Vol 17, No 4, p541-555 
come to explain their involvement to others in their constituency once the taskforce's report had been published. The power relations that were affecting the meeting were imagined and anticipatory (Wright Mills, 1959).

The examples of jolting, that I describe here, occurred a number of times and reframed the conversations ranging from bewilderment, agreement, threatening to walk out and shared understanding. Without these there would have been no progress, but similarly there was risk of the project unfurling. These processes of creative unsettlement were not predictable, but from conversations with the chairperson she worked hard to understand and get close to the different communities.

The conversations in the taskforce took place in near confidence; despite rules of secrecy it was porous. People were included and briefed according to their power and influence. In this process different groups developed an understanding of the needs of others, for example the ethical concerns that some in intensive care had over the care of the organ donor after death, in processes of inclusion and exclusion (Elias and Scotson, 1994).

Also apparent was the nature of the interaction between unnoticed assumptions shared amongst individuals in groups and how these became available to notice and discuss in changing power relations. As insights became apparent in conversation these came to further affect individuals which in turn would affect others and so on in a complex process. The taskforce, being a temporary organisational/organising entity, did not have the heritages of power relations of the established organisations from which the participants were drawn. These included for example, professional medical bodies, universities, and healthcare organisations. Some of these organisations could draw on several hundred years of history. Over a period of time each taskforce member co-developed and had become increasingly expert in new rules of relating to each other, including those from different professional communities. Participants' social capital, as defined by their own professional identities and groupings, became infused with that of others. This was not expertise, but a novel exploration of each other's patterns of relating. In so doing participants noticed and questioned those processes of professional intuition and identity. Pierre Bourdieu (Bourdieu, 1990), sociologist and anthropologist, introduced the term habitus to refer to the aspects of a game internalised as part of becoming expert in which one intuitively 'reads' the social situation with the ability to discern the next probable best course of action. But with this intuition comes a reduced ability to notice the social norms of which they are part. In joining the taskforce the participant does not lose this ability but has the potential to form new and overlapping habitus with those in professions adjunct and critical to the joint endeavour, hence the occasional jolting. New ways of understanding are developed in the taskforce but in doing so the individuals are mindful of those in their established habitus. Here there is tension, not losing face in either becomes important, and the tension shifts in its unpredictability from the group forming and understanding (the internal dynamic) to how the emerging consensus can be explained (the external dynamic).

\section{Page 9 of 18}

Warwick R (2016) Routine innovation: complex processes from policy development to implementation, International Journal of Business and Globalisation, Vol 17, No 4, p541-555 
Narrative: The taskforce presents - the public strategy consensus

Following taskforce consensus on a series of recommendations and agreement with ministers, the second narrative, in two parts, describes the launch of the taskforce's findings and recommendations. The narrative describes the confidence and clarity of the message presented by the chairperson. It goes on to explain how these messages were starting to be interpreted within the context of people's day-to-day activity. And it was here that further twists of innovation were starting to occur.

In terms of innovation there was little new in the fourteen recommendations made; they had appeared in other reports. The one thing that was different was the nature of the relationships between different established groups and the power relations within and between those groups. The routines by which they related to each other had now changed.

\section{Clarity of Presentation}

The chairperson began to speak. Viewed from the back of the room, the haphazard arrangement of people sitting on chairs in the foreground was in marked contrast to the neat backdrop and large desk, white table cloth and carefully arranged bottles of water from where the chairperson and a couple of others were giving their presentation.

Here the strategy and recommendations were presented in a confident and direct way. Other than recognising that all the fourteen recommendations were important if the aim of the strategy was to be achieved, there was little recognition of how the recommendations would mesh together or fit within the wider picture. They were presented as clear and discrete areas of work that had been carefully thought out in the deliberations of the taskforce. Confidence and clarity were as important if people in the room and beyond were to be convinced that the changes were to be made. The presentation finished and we left. Those present signed up to a $50 \%$ increase in productivity in five years, a figure that they were to come back to and re-interpret later on in a more informal setting.

There are a number of important themes here. Firstly, in contrast to the conflict between participants and their vicarious communities the presentation of the taskforce was a moment of cohesion and performance. The public theatre of consensus (Goffman, 1959) masked the unstable power relations of the group and its workings, particularly behind the scenes. The report was presented with clarity and confidence that the objectives would be met. This was an implicit recognition of a shifting power figuration beyond the group and that the taskforce had now done its work. The chairperson was interviewed on the BBC Radio 4's flagship news programme Today. Here again clarity and the benefits were emphasised and the challenges of bringing this about were not mentioned.

\section{Messiness of interpretation}

The question now became how the recommendations were to be made sense of. Each recommendation was only a few lines in length, kept short for clarity and with some difficult issues deliberately unanswered because of a lack of agreement in the taskforce. An example

Page 10 of 18

Warwick R (2016) Routine innovation: complex processes from policy development to implementation, International Journal of Business and Globalisation, Vol 17, No 4, p541-555 
of this occurred a few minutes after the end of the launch when conversations started to occur in the room. The audience, many of whom were in the transplant community, shifted their chairs to talk with their friends and colleagues; the low level chatter could be heard during the presentation and would later be marked by a scattering of paper, bags and coffee cups that would litter the floor. It was here for example that conversations occurred as to how many staff would be required to do certain jobs, as was the case with the following conversation that I was part of:

I was sitting next to John (not his real name), a professor of transplantation. Next to him was a chief NHS medical person. John had a brief conversation with this person and asked how many more surgeons they would require. John, off the top of his head, thought of a number. This number has now been ingrained in official policy. Both John and this person were there of their own free will. However, both knew of the constraints within the taskforce recommendations. Neither constraint or freedom were present in isolation, both were bound together. Subsequently this helped form a context whereby the ambiguity of the recommendations was made sense of. Indeed, it was made sense of within a far wider network of relationships than that of the taskforce.

The work of the taskforce enabled these discussions to occur but they were not in control of them. From the Minister's perspective the assurance and clarity was important to enable commitment and funding. What I'm pointing to are the differing ways that the recommendations were used in the various communities: clarity and targets were important for those providing political support and funding; with detail left unsaid to provide for freedom for those implementing actions on the ground. Here the routine of innovation was experienced differently. The argument for funding and the recommendations needed to be couched in terms of fitting in with the routines of government process; of budget, assurance and political rhetoric, all requiring the theatre of confidence and clarity.

Narrative: Exploring the recommendations with the 'experts'

Several months after the taskforce launch people at the front-end of organ donation were involved in their own round of understanding the implications of policy in relation to their practice. The propositional themes of the taskforce, the additional scrutiny and the changes in power relations caused further shifts in the pattern and intensity of relations from which new working relationships were emerging. Donor Transplant Coordinators (DTCs), as they were then called, were senior nurses who spoke with the families of the deceased to gain consent for organ donation and to make various arrangements. I was asked to chair two workshops. These were high profile and were a consultation exercise on how the DTCs would work differently in order to deliver the benefits envisaged by the taskforce.

I am going to focus on the workshop that was held in London, particularly the question and answer session. My role as a facilitator at this point was to field questions between the participants and a panel of directors and others who had been working on this particular area.

Page 11 of 18

Warwick R (2016) Routine innovation: complex processes from policy development to implementation, International Journal of Business and Globalisation, Vol 17, No 4, p541-555 
The day progressed well until I asked the DTCs to discuss the outline job descriptions that had been prepared. It was to be a common format for both workshops: work through the material, discuss with peers a number of questions, and report back to the wider group. I had felt the tension building up to this point for a couple of hours. The DTCs were desperate to see the details of how, it was being envisaged, they would be working in the future. Over the previous few months we had been developing the draft job descriptions, including the likely pay banding, and some of the detail of how the DTCs would be working in practice. I had lobbied that before the workshop we should send the job descriptions to the DTCs so there were not too many surprises. This idea was rejected on the basis that some people were uneasy to give the impression to the DTCs that work had been done before the event. The beginning of the workshop session was like a flood of emotional anxiety aimed at me as facilitator, anxiety focused on why the job descriptions had not been sent out before and what was being hidden. I felt a sense of sharpness and acuteness. What I find interesting, as I write this, is that I can still feel that sense of energy. The questions and feedback focused on: why was the job role to be split? This would be seen as a devaluation of the DTC role; the removal of a recipient co-ordination role would remove a lot of job satisfaction, there were questions on the robustness of service, career progression and where the additional staff would come from. There were also questions relating to important personal issues such as the loss of on-call money, transfer to a new employer and moving away from teams where relationships and friendships had developed over many years. During the workshop I was aware of how the questions developed and were built upon by others in the room and how some points kept coming up time and time again, whilst others emerged and faded away. Also, how the conversation often focused around a few vocal individuals.

During this I noticed a shift. At the start those with the upper hand, in terms of seniority within the organisation, appeared confident in presenting their view of the future. The projected slides were accompanied with polished explanations of the future. It was in the question and answer section that I noticed how control shifted and flexed throughout the room. It was in those moments that I saw little in the way of power and confidence that had accompanied previous presentations, particularly at the Department of Health, discussed earlier in the paper.

There were many meetings over the two year period some of which I was invited to and attended and others that I did not. Notice the contrast of routine; previously assimilation into existing governmental routine was important but here it was different. In the establishment of new routines there was a similar sense of jarring as experienced in the taskforce as power relations shifted.

For the government policymaker innovation is important not only to enable the growth economies but also in the delivery of more efficient public services. What I am drawing attention to are the processes by which propositional themes are developed, often facilitated by changing the routines by which people relate to each other. These propositional themes are

Page 12 of 18

Warwick R (2016) Routine innovation: complex processes from policy development to implementation, International Journal of Business and Globalisation, Vol 17, No 4, p541-555 
created, often with ambiguities, to be made sense of in different communities which in turn go through similar processes. The connections between government policy making and frontline delivery can be long and complex with many different groups to influence, each with their own power figurations and identities.

The issue of routine is important both in its stability and instability. And it is here that the policymaker has some agency expertise in one's practice, or habitus. This leads to a reduced ability to notice the norms, long held assumptions and behaviours of which one is part. The formation of a taskforce, comprising of different groups, enables noticing to occur within and between one's fields. This develops new awareness and understanding. However, because of a lack of organisational routine and power structure in which participants have developed a shared expertise, it is unstable. This instability is paradoxically vital as an impetus for sense making, developing consensus and decision-making. The instability was on people's minds as they made the next step. Sometimes this led to a jolt and a new alignment of power figurations. At other times it was imagined and led to gestures, such as bringing cakes that drew the group together. The temporary organisational structure of the policy group, with its rules of confidentiality, allowed conversations to be had in a way that saved face in the context of instability. As people worked in the taskforce the identity shifted both in terms of: public association with a high-profile policy group; and, with a foot in the professional community and how the developing consensus would be seen. In this sense power figurations were being played out both in the taskforce room and as imagined in the wider communities. Paradox included the stability and instability of the group and the changing identity of allegiances between the taskforce members. These processes were evident throughout, masked with occasional rhetoric of clarity and assurance. These were important to maintain confidence of sponsors and interested parties. Those involved in the policy process needed to be mindful of these routines and were careful to ensure an adequate performance.

Complex responsive processes of relating provides a way to notice and discuss these ongoing and sometimes confusing ways of human engagement. An appreciation of paradox was important, not in seeking the resolution in the reconciliation of competing forces, but accepting and working with its transformative potential. There is also an understanding of how propositional themes are developed and passed to others for further interpretation and work.

\section{$5 \quad$ A spatial perspective of systems complexity}

In this section I will discuss alternative ways of thinking about complexity. People talk of systems as a way of understanding an organisation (Jackson, 2003; Seddon, 2005, 2008) an economy, a sector etc. It is a way of thinking that allows for connections and interactions to be considered and pays attention to the non-linear and complex dynamics that can play out. However, assumptions on systems have important implications for how we think of our relationship with others and our involvement in that system. Drawing examples from ecology, biology, complexity theory and cybernetics there are a number of ways of defining a system. A common thread is that a system is characterised by a number of parts (or nodes)

Page 13 of 18

Warwick R (2016) Routine innovation: complex processes from policy development to implementation, International Journal of Business and Globalisation, Vol 17, No 4, p541-555 
and interactions between those parts result in a complex dynamic that is hard to predict from initial conditions. So, the number of the parts as well as the speed of interconnection between them comes to affect the dynamic of the system in ways that are difficult to control.

The problem, and underlying assumption, is that some see a system as having a boundary between the activities and an external 'non system' (Jackson, 2003, p9-10). The implication is that a person can be under the impression that they can stand outside and can control what happens, in other words to independently change the variables without themselves being affected. It draws attention to the spatial (observer outside, the observed inside) rather than the temporal flow of events that I have drawn attention to, of which we are all a part, including the enquirers. It plays down issues of paradox, confusion, anticipation, hope and fear; the issues that I have discussed above. Approaches that rely on 'perfect' information implied in the stance of the detached observer are fraught with disappointment particularly if they are at the expense of developing a conscious awareness of the dynamics of the 'now'. The writings of the systems thinker and operational researcher, Stafford Beer, are telling. In his collection of essays (Beer, 2009) he describes his work with the Chilean president Salvador Allende in the 1970s. Under Beer's guidance computers were installed to predict and control the Chilean economy. Circular causal relationships were there to be identified and controlled, leading to prosperity and social justice. What could not be controlled were external economic and political factors. There was a coup, facilitated by its powerful neighbour to the north and Allende died. Stafford Beer was deeply affected by the events and failure of the system.

A spatial emphasis on systems complexity pays little attention to power in terms of how the actors interact with each other. It down plays those animosities, hopes and fears that are drawn from previous experiences and how these come to shape our expectations as we engage with others.

\section{Conclusion}

The case I presented spanned two years and led to new ways of working. The policy recommendations, the overt task that was given, did not come up with anything new. For the policymaker the implication is to focus both on policy and how people relate to each other in making sense of propositional themes in their context. For this, attention needs to be paid to how group(s) are formed, the authority they have to interpret and the ongoing facilitation of stability/instability. In doing so it enables the noticing of habitus, power structures and identity and the proto-formation of new ones. It is this that will enable the development of recommendations as gestures that will be responded to in the acts of social imagination. In this sense implementation is already starting at least in the minds of those involved, including provisional displays of commitment (Kiesler, 1971, p167-177), (Weick, 1995, p157-162).

\section{Acknowledgements}

\section{Page 14 of 18}

Warwick R (2016) Routine innovation: complex processes from policy development to implementation, International Journal of Business and Globalisation, Vol 17, No 4, p541-555 
The author would like to thank Alfons de Laat for the conversations during the summer of 2014 that made this paper possible. 


\section{References}

Alvesson, M. and Spicer, A. (2012), “A Stupidity-Based Theory of Organizations”, Journal of Management Studies, Vol. 49 No. 7, pp. 1194-1220.

Baregheh, A., Rowley, J. and Sambrook, S. (2009), "Towards a multidisciplinary definition of innovation”, Management Decision, Vol. 47 No. 8, pp. 1323-1339.

BBC. (2013,April11), "Donor increase is 'phenomenal achievement"”, BBC News, London, available at: http://www.bbc.co.uk/news/health-22104794 (accessed 10 August 2015).

Beer, S. (2009), Think Before You Think: Social Complexity and Knowledge of Knowing, Wavestone Press, Oxford.

Bourdieu, P. (1990), The Logic of Practice, Polity Press, Cambridge, UK.

Brighton Fuse. (2014), “The Brighton Fuse Final Report”, available at: http://www.brightonfuse.com/the-brighton-fuse-final-report/ (accessed 10 August 2015).

Brighton Fuse. (2015), Freelancers in the Creative Digital IT Economy Brighton Fuse 2, available at: http://www.brightonfuse.com/wpcontent/uploads/2015/01/brighton_fuse2_online.pdf (accessed 10 August 2015).

Burkitt, I. (1991), Social Selves - Theories of the Social Formation of Personality, Sage, London.

Checkland, P. and Poulter, J. (2006), Learnign for Action - A Short Definitive Account of Soft Systems Methodology and its use for Practitioners, Teachers and Students, John Wiley \& Sons, Chichester.

Cunliffe, A.L. (2002), "Reflexive Dialogical Practice in Management Learning”, Management Learning, Vol. 33 No. 1, pp. 35-61.

Cunliffe, A.L. (2009), "The Philosopher Leader: On Relationalism, Ethics and Reflexivity--A Critical Perspective to Teaching Leadership", Management Learning, Vol. 40 No. 1, pp. 87-101.

Elias, N. (1978), What is Sociology?, Columbia University Press, New York.

Elias, N. (2000), The Civilizing Process, (Dunning, E., Goudsblom, J. and Mennell, S.,Eds.), Blackwell Publishing, Oxford, Second.

Elias, N. and Scotson, N. (1994), The Established and the Outsiders, Sage, London, Second.

Ellis, C. and Bochner, A. (2000), “Autoethnography, personal narrative, reflexivity Researcher as subject", in Denzin, N. and Lincoln, Y. (Eds.), Handbook of Qualitative Research, Sage Publications, Thousand Oaks, London, New Delhi, 2nded., pp. 733-768. 
Fonseca, J. (2002), Complexity and Innovation in Organisations, Routledge, London and New York.

Franklin, P. (2007), "Explication: working to discover and share new knowledge from prior experience", Journal of Workplace Learning, Vol. 19 No. 1, pp. 45-54.

G. H. Mead. (1934), Mind, Self, \& Society, Chicago University University, Chicago.

Goffman, E. (1959), The Preservation of Self in Everyday Life, Penguin, London.

Griffin, D. (2001), Emergence of Leadership - linking self organization and ethics, Routledge, Abingdon, UK.

Jackson, M. (2003), Systems Thinking - Creative Holism for Managers, John Wiley \& Sons, Chichester.

Johnson, P. and Duberley, J. (2003), "Reflexivity in Management Research *”, No. July.

Kiesler, C. (1971), The Psychology of Commitment - Experiments Linking Behavior to Belief, Academic Press, New York and London.

Kreiner, K. (2002), “Tacit knowledge management: the role of artifacts", Journal of Knowledge Management, Vol. 6 No. 2, pp. 112-123.

Lackoff, G. and Johnson, M. (2003), Metaphors We Live By, Chicago University University, Chicago.

MacKenzie, R. and Franklin, P. (2006), "Prologue: Towards an Understanding of Explication", Organisations and People, Vol. 13 No. 1, pp. 3-5.

Mayer, R.C., Davis, J.H. and Schoorman, F.D. (1995), “An Integrative Model of Trust”, The Academy of Management Review, Vol. 20 No. 3, pp. 709-734.

Mead, G. (1932), The Philosophy of the Present, Prometheus Books, Amherst, New York.

Möllering, G. (2006), Trust: Reason, routine, reflexivity, Elsevier Ltd, London.

Orwell, G. (1949), Nineteen Eighty Four, Penguin, Harmondsworth.

Polanyi, M. (1958), Personal Knowledge - Towards a Post - Critical Philosophy, Chicago University University, Chicago.

Ramsey, C. (2014), "Management learning: A scholarship of practice centred on attention?”, Management Learning, Vol. 45 No. 1, pp. 6-20.

Revans, R. (1998), ABC of Action Learning: Empowering Managers to Act and to Learn, Lemos and Crane. implementation, International Journal of Business and Globalisation, Vol 17, No 4, p541-555 
Seddon, J. (2005), Freedom from Command and Control: Rethinking Management for Lean Service, Productivity Press, New York.

Seddon, J. (2008), Systems thinking in the public sector, Triarchy Press Limited, Axminster.

Shaw, P. (2002), Changing Conversations in Organizations - A Complexity Approach to Change, Routledge, Abingdon, UK.

Stacey, R. (2003), "Learning as an activity of interdependent people", The Learning Organization, Vol. 10 No. 6, pp. 325-331.

Stacey, R. (2007), Strategic Management and Organisational Dynamics - The Challenge of Complexity, Prentice Hall, Harlow, Fifth.

Stacey, R. and Griffin, D. (2005), "Experience and method: a complex responsive processes perspective on research in organisations", in Stacey, R. and Griffin, D. (Eds.),A Complexity Perspective on Researching Organizations - Taking experience seriously, Routledge, London.

Stacey, R., Griffin, D. and Shaw, P. (2000), Complexity and Management - Fad or Radical Challenge to Systems Thinking?, Routledge, Abingdon, UK.

Streatfield, P. (2001), The Paradox of Control in Organisations, Routledge, London and New York.

The Department of Health. (2008), "The potential impact of an opt out system for organ donation in the UK: an independent report from the Organ Donation Taskforce", available at:

http://webarchive.nationalarchives.gov.uk/20130107105354/http:/www.dh.gov.uk/en/Pu blicationsandstatistics/Publications/PublicationsPolicyAndGuidance/DH_090312 (accessed 15 January 2015).

Warwick, R. and Board, D. (2012), "Reflexivity as methodology: an approach to the necessarily political work of senior groups", Educational Action Research, Vol. 20 No. 1 , pp. 37-41.

Weick, K.E. (1995), Sensemaking in Organizations, Sage, London.

Wright Mills, C. (1959), The Sociological Imagination, Oxford University Press, Oxford. 